\title{
Economic Mathematical Modeling of Attributed Costs of Production in Industrial Enterprises
}

\author{
Mikhail Nikolaevich Dudin ${ }^{1}$, Nikolaj Vasil'evich Lyasnikov ${ }^{1}$, Dzhurabaeva Gulnora Kahramanovna ${ }^{2}$ \& \\ Dzhurabaev Kahraman Tursunovich ${ }^{2}$ \\ ${ }^{1}$ Russian Academy of Entrepreneurship, Moscow, Russian Federation \\ ${ }^{2}$ Novosibirsk State Technical University, Novosibirsk, Russian Federation \\ Correspondence: Mikhail Nikolaevich Dudin, Russian Academy of Entrepreneurship, Moscow, 105005, Russian \\ Federation. E-mail: dudinmn@mail.ru
}

Received: December 18, 2014

Accepted: December 29, $2014 \quad$ Online Published: July 6, 2015

doi:10.5539/mas.v9n8p40

URL: http://dx.doi.org/10.5539/mas.v9n8p40

\begin{abstract}
Statement of a problem: the present article is theoretical and methodological research focused on analysis and provisioning the basics for using different approaches to economic mathematical modeling of attributed costs of production in industrial enterprises. Approach: in its methodological part the article is based on a set of economic mathematical modeling methods. In particular, method of graphical simulation was used as well as regression modeling method.

Research results allow making conclusion that using graphical approaches to modeling of attributed costs of production does not always provides relevant and objective results. Authors prove that the best and the most practical way is to use regression and correlation modeling methods in managing cost prices.

Conclusion/recommendations: materials provide in this article are an addition to general management theory as well as extension of theoretical and methodological basis of production management. Main theoretical and methodological results obtained in the work are recommended as development platform for making high quality and effective management decisions in modeling cost price, volume of production and revenue of an enterprise.
\end{abstract}

Keywords: cost price, manufacturing facilities, economic mathematical modeling, econometric approach, graphical analysis, regression analysis

\section{Introduction}

Production activity management of today industrial enterprises is getting more and more complicated (Limitivski, 2010). Both internal and external factors contribute complicating specifics of production activity management of today industrial enterprises. Among external factors there is at first shift of global social and economic trend and transition to knowledge economy. Not the less important factor is change of management paradygm for the one with dominating role of innovative activity and sustainable development of industrial enterprises (Mochalova, 2010). Internal factors that affect specifics of industrial enterprise's functioning in external environment may be viewed in functional, process and system dimensions. But the most important is income, costs and revenue management because availability and sufficiency of financial resources is the basis of innovative-driven sustainable development of today industrial enterprises (McConnell \& Bru, 2009).

The ongoing geopolitic processes reduce capability of today enterprises to generate high earnings growth rate of operational (core) activity. Besides, many enterprises have limited capability to raise external funding (Limitivski, Lobanova, Palamarchuk \& Minasian, 2012). So changes of external environment point on the necessity not only of the search for new markets but also of preserving and increase of profitability. Preserving of relevant profitability level in the situation of limited capabilities to gain revenue depends on attributed costs management.

From economic point of view cost price is a money term of all costs and expenses that enterprise has bear for production and sales (Drury, 2010). Enterprise's costs management (or attributed costs management) is the process focused on streamlining of operational budget related to core activity. Streamlining of operational budget is one of the main conditions of revenue level growth while preserving or reducing of operational budget level. It 
is worth noting that in scientific sources it is often stressed the fact that costs and expenses are not identical concepts (Limitivski, Lobanova, Palamarchuk \& Minasian, 2012). On one hand it is true because costs may be both tangible (including money) and intangible. Expenses (including attributed costs of industrial enterprises) are represented only in money terms.

But on the other hand considering spending bear in operational activity enterprise put all of them in one form and in this case this form is price. So one may speak that expenses of industrial enterprise related to forming of cost price of products are evaluated in money terms all the resources spent.

\section{Methodology}

This article is methodologically represented by a set of methods of economic mathematical modeling. As related to practical calculations, an approach based on the correlation of two or more factors describing the specific nature of a separately taken enterprise's activity was used.

Bifactorial economic mathematical model describing dependence between cost price and production volume may be the following (Popov \& Sotnikov, 2012):

$$
Y=\alpha+\beta_{x}
$$

Relation between variables $X\left(x_{1}, x_{2} \ldots x_{n}\right)$ and $Y\left(y_{1}, y_{2} \ldots y_{n}\right)$ is set by means of correlation analysis and factors' impact level is determined ad also it is determined the reliability of the proposition that factors are interrelated. Such indicators as co variation factor, pair correlation coefficient, dispersion coefficient, coefficient of determination, coefficient and others may be calculated in the course of analysis.

Coefficient $\beta$ is calculated according to the formula (Popov \& Sotnikov, 2012):

$$
\beta=\frac{\sum_{i=1}^{n}\left(x_{i}-\dot{x}\right) *\left(y_{i}-\dot{y}\right)}{\sum_{i=1}^{n}\left(x_{i}-\dot{x}\right)^{2}}
$$

Coefficient $\alpha$ is calculated according to the formula, respectively, [15]:

$$
\alpha=\dot{y}-\beta_{x}
$$

\section{Results}

Activity of today industrial enterprises is highly determined. Industrial production in Russia in the last couple of years is not characterized by sufficient positive dynamics.

At the same time there was no significant falls of industrial production index in Russia during 2014. Moreover, for some months industrial production indexwas higher comparing the same periods of 2013 (see Figure 1).

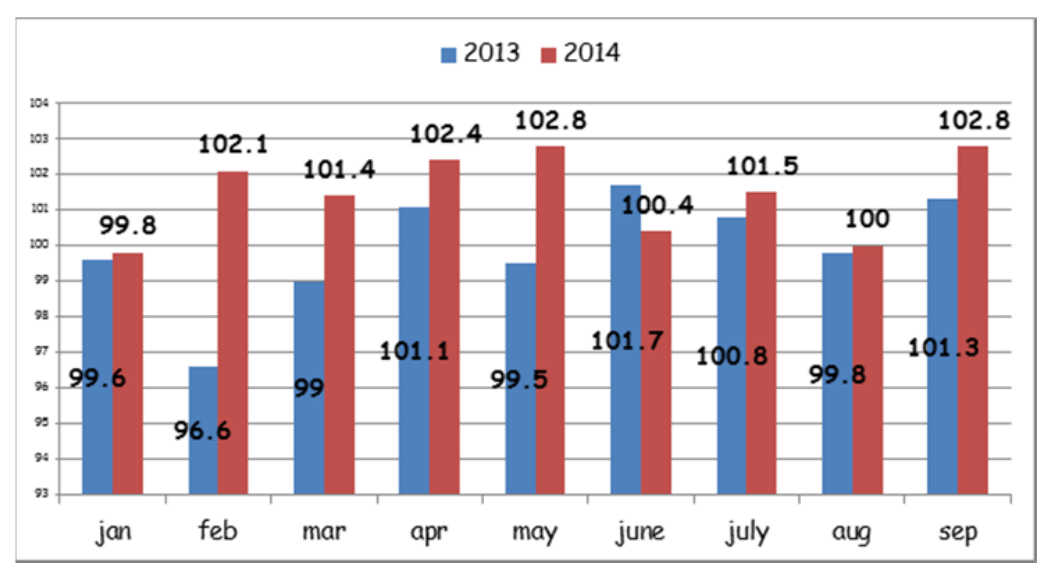

Figure 1. Industrial production index dynamics in Russia in 9 months of 2013-2014 (Index of industrial production. Federal Statistics Agency. www.gks.ru/bgd/free/b00_24/IssWWW.exe/Stg/d000/I000010R.HTM)

It is obvious that there is no forecasted stagnation of Russian industry against ongoing geopolitic changes in 2014, although the value of Russian index is somehow lower that American and European indicators (see Figure 2). Rate of industrial production volumes decrease in Germany in last two months of 2014 may be considered significant. It is obvious that geopolitic factors affecting activity and development of industrial enterprises have bilateral character. 


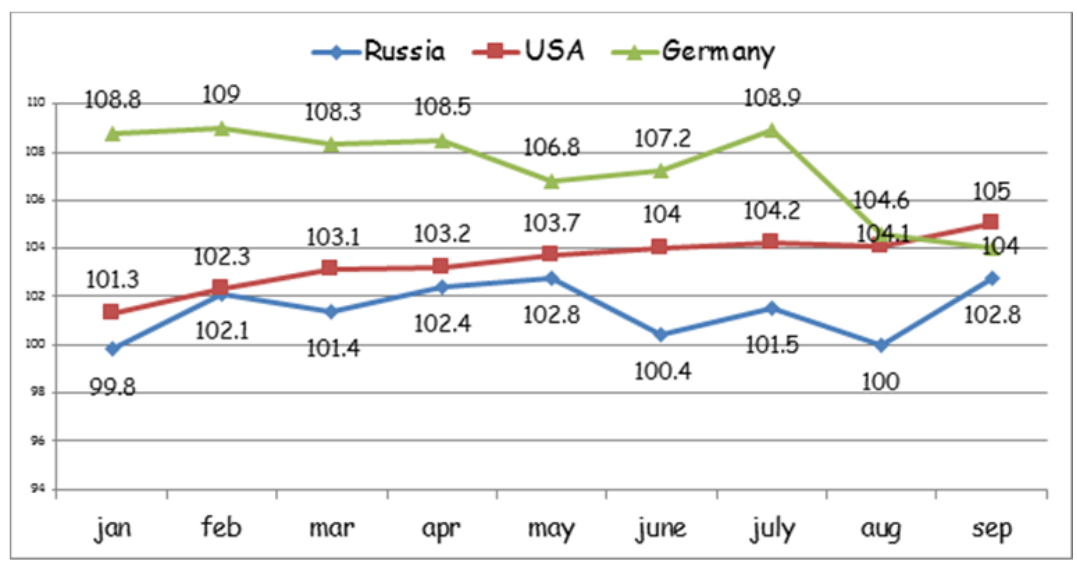

Figure 2. Industrial production indices in the USA, Germany and Russia in 9 months of 2014 (USA Industrial Output. Quote RosBusiness Consulting. www.quote.rbc.ru/macro/indicator/24/98.shtml; German Industrial

Output. Quote Ros Business Consulting. www.quote.rbc.ru/macro/indicator/26/228.shtml)

So, today industrial enterprises in the world now face the same problems related to limitation of capabilities to generate revenue and at the same time necessity to preserve or increase revenue level that may be invested in further development.

So effective costs management (or expenses management) to provide appropriate and necessary to support the growth level of profitability of industrial enterprise operation becomes the most important managerial function. It is also necessary to make sure that all the costs (expenses) of industrial enterprise attributed to cost price are manageable. The answer is obvious - industrial enterprise (more precisely its management) is not always capable to manage all operational costs and expenses in planned and purposeful manner.

The reason is that in practice management of costs attributed to cost price is viewed as the necessity to reduce it. But managers often lose of sight that cut of expenses in operational activity of industrial enterprise may cause partial decrease in quality of products and loss of competitive advantage. Correlation between the greatest possible cut off attributed costs and such indicators as the quality of products, competitive advantage of an enterprise is objective and obvious.

Purchases of resources (both tangible and intangible) that support operational requirements of production are necessary to produce required volume of products of relevant quality (Total Cost Management Framework, 2012). Reduction of attributed costs usually causes choosing more cheap resources that affects the quality of products. Decrease of quality in turn leads to the loss of competitive advantage of industrial enterprise in external environment because the products of lower quality (even when these products are cheaper) means loss of customers' loyalty and draught of customers to competitors (Ross, Westerfield \& Jordan, 2000).

So, critical cut of costs of industrial enterprise for resource provisioning in operational activity is absolutely wrong approach. To keep the balance of economic growth and sustainable development industrial enterprise should be capable to model effects of optimization of costs for resources and of sales products in managing operational costs.

Modeling as a special instrument of management is widely used in managing activity of today industrial enterprises (Limitivski, 2010).

In theory model is analogous to real physical process or object with keeping features and patterns of its functioning and development. So economic modeling (including modeling operational attributed costs) may be viewed as process focused on reproduction of analogue of operational activity of industrial enterprise with keeping the relation of resources utilization and production of necessary volume of products with required quality.

It is accepted that attributed costs in the scope of production activity of industrial enterprise are classified by items of calculation and items of expenses (Cooper, 1990). Theoretical classification of operational budget (attributed costs and costs of sales) of industrial enterprise is shown in Figure 3.

It is obvious that in some cases calculation items and expense items attributed to price cost of operational activity of industrial enterprise are the same. So the most relevant approach is dividing costs by permanent and variable (i.e. dependent and independent of production volumes). Classification of costs attributed to cost price 
of production and sales of industrial enterprise is the base of selection of the method of costing.

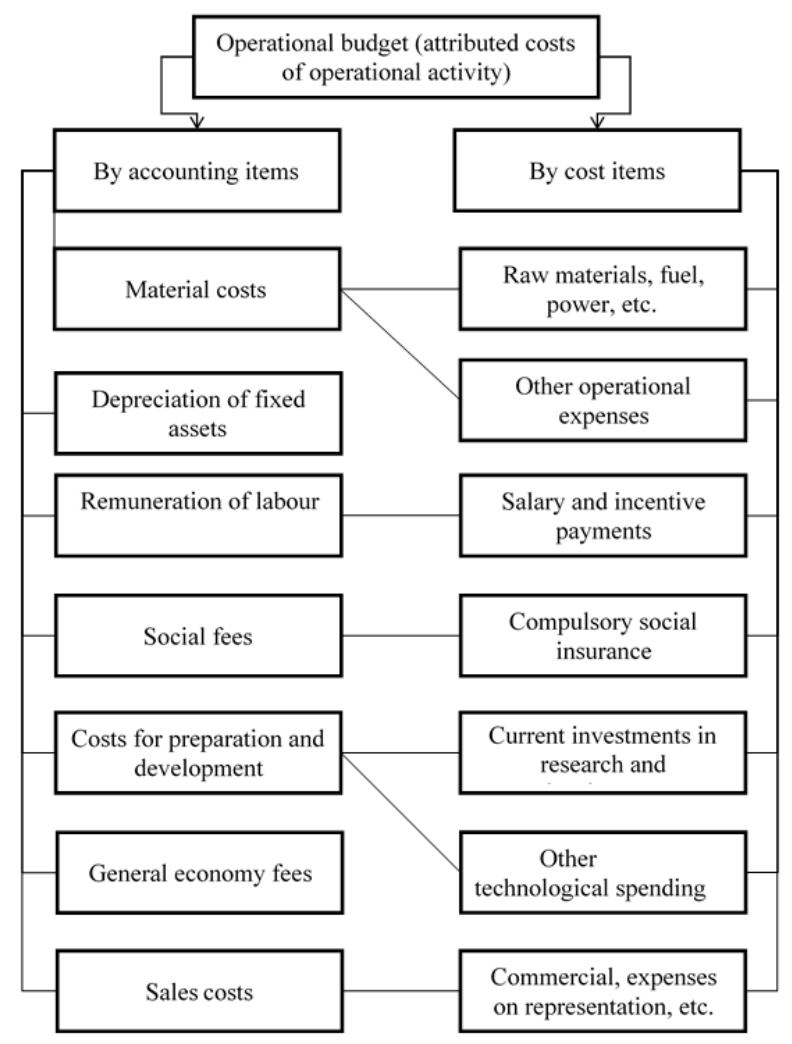

Figure 3. Classification of operational budget (attributed costs) of industrial enterprise

In particular, it is accepted to distinguish between several methodological approaches to costing (Cooper \& Kapla, 1991):

- $\quad$ standard costing is costing method that may be defines as normative. In other words standard costing is normative resource usage in money terms necessary to product an item of production (and planned volume of products, respectively). Key idea of standard costing method is that industries in which resources usage cost for production and sales is not subjected significant variations may develop standards of costs and expenses. These standards are used as the basis for planning activity of industrial enterprises and evaluate deviations;

- $\quad$ direct costing is costing method based on separation of the latter on direct and indirect costs. Direct costs are costs that are directly related to production volume (i.e. are direct variable costs). Indirect costs, respectively, are not related to cost price of production and sales and do not depend on production volume (i.e. are indirect permanent costs). Direct variable costs are usually included in cost price in direct costing although there is a concept of advanced direct costing when both direct variable and indirect variable costs are included in cost price;

- $\quad$ target costing is costing method based on calculation of target cost price. Target costing is usually used in development and marketing new products, including innovative products. Unlike normative approaches to costing target costing method presupposes setting target reference point for production and sales to offer competitive product not only by quality but also by price. In other words target costing method allows making optimal price/quality ratio basing on target expenses related to production and sales.

This list of costing methods is far from being comprehensive. In particular, such methods as «Justin Time», «ABC-cost» and many others methods and models may be named. To our mind each of listed costing methods for evaluation of price cost of operational activity has its advantages and drawbacks. In particular, normative costs of production per one item or the whole volume of products in condition of turbulent changes of environment and resources' prices does not allow adaptively approaching planning of operational activity of industrial enterprise. Setting target volume of attributed costs of operational activity reduces the number of 
variants of customer stimulation (in this case price stimulation) that may have negative impact on customers' perception of products.

At the same time separation of costs and expenses related to cost price of operational activity of industrial enterprise in permanent and variable allows not only adapting planning procedures to changing external conditions but provide required balance of resources considering possible linear and non-linear trends of prices variations and prices of these resources.

\section{Discussion}

It is commonly thought in macro- and microeconomy that increase of production volumes means reduction of cost unit (price cost of production of production unit) due to economy of scale (Deakins, Logan \& Steele, 2001). But at the same time standard CVP model (model costs-volume-profit) is based on the principle of variation of one parameter with invariability of two other parameters (or with directly proportional variation of these parameters depending on changes of variable parameter) that makes this model linear (see Figure 4).

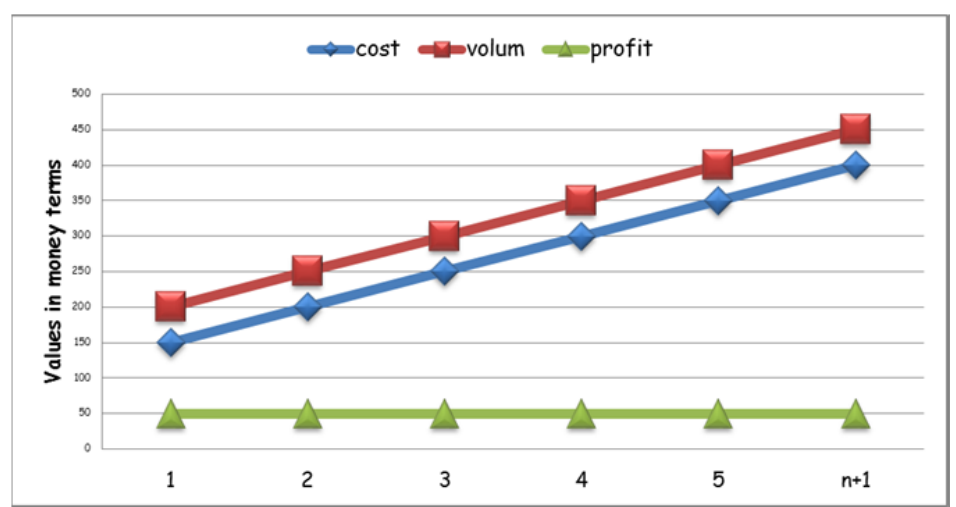

Figure 4. Linear representation of CVP model (model costs-volume-profit)

In ideal view of CVP model in each further period with increase (or cut) of costs production volume proportionally grows and revenue level remains the same.

\subsection{Graphic simulation of cost price}

But taking into consideration non-linear character of changes going on in external environment of industrial enterprise cost unit per unit of production may be characterized by converse effects (see Figure 5). It is obvious that growth of production volume (from $\mathrm{V}_{1}$ to $\mathrm{V}_{2}$ ) cost unit per production unit may reduce but after passing a certain turning point further increase of production volume (from $V_{2}$ to $V_{3}$ ) may cause reverse effect.

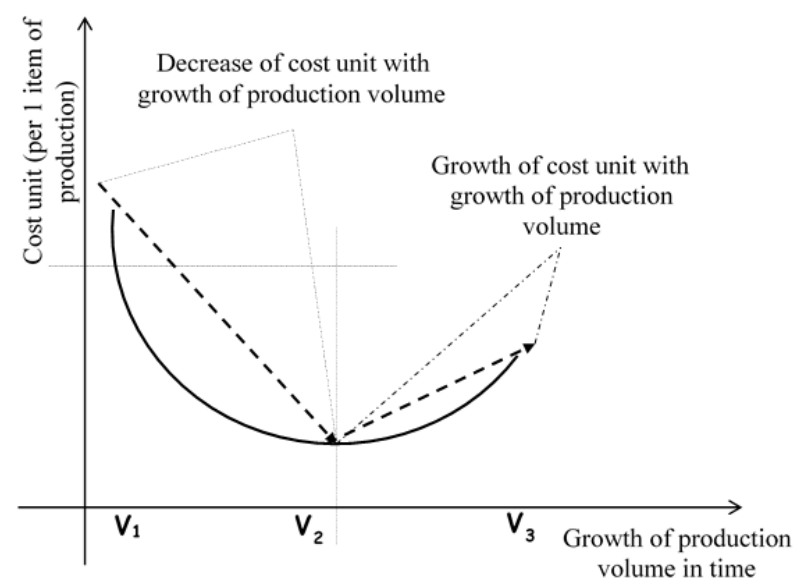

Figure 5. Non-linear change of cost unit of production with production volume growth

The essence of this converse effect is that despite any increase of production volume cost unit and, respectively, aggregated attributed costs always demonstrate higher comparative growth. And moreover, it is obvious that always the level of aggregated costs and expenses attributed to price cost of production and sales grows with the 
growth of production volume.

The following dependence may be derived as the ratio of cost price and production volume (sales) changing. Figure 6 shows buoyant dynamics that characterizes the growth of production volume and proportional growth of cost price.

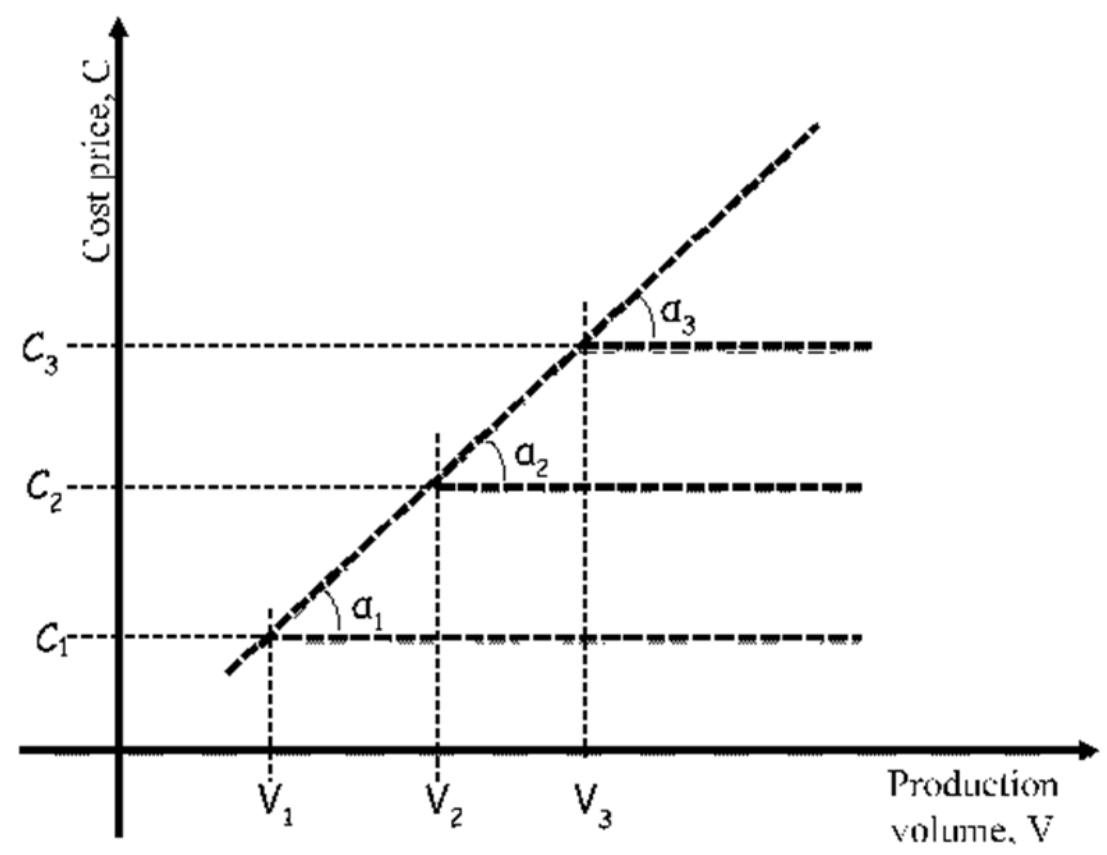

Figure 6. Graphic of dependence of cost price change in respect to change of production volume on industial enterprise

Reverse situation (decrease of production volume and proportional decrease of cost price) requires independent analysis, but bearish trend is described in the same way. So each next crossing of lines and trend of sales volume change will form an angle (in our case this angle is denoted as $\alpha_{1}-\alpha_{3}$ ). It is commonly considered that angle formed by lines $\mathrm{C}_{\mathrm{n}} ; \mathrm{V}_{\mathrm{n}}$ and their change trend is $45^{\circ}$ and it has conditionally constant value defined as $\alpha\left(\operatorname{tg}_{\alpha}\right)$ angle tangent, i.e.:

$$
\angle \alpha\left(45^{\circ}\right)=\frac{\sin _{\alpha}}{\cos _{\alpha}}=\operatorname{tg}_{\alpha}=1
$$

But this is not constant because usage of resources included in cost price and change of production volume are not characterized by a priori proportional or linear character. So angle formed by lines $C_{n} ; V_{n}$ and their change trend (angle $\alpha$ ) is not always $45^{\circ}$ and is 1 . From geometry it is known that tangent of any angle varies from 0 (for angles $0^{\circ} ; 180^{\circ} ; 360^{\circ}$ ) to infinity (for angles $90^{\circ} ; 270^{\circ}$ ). So change of cost price depends on changes of production volumes, adjusted by the factor of business activity of an enterprise. Factor of business activity in this case equals the value of tangent of angle $\alpha\left(\operatorname{tg}_{a n}\right)$. So, calculation of costs and expenses attributed to cost price of production and sales may be represented as:

$$
C_{t}=C_{p}+\Delta V_{t} * k\left(\operatorname{ortg}_{a}\right)
$$

Where:

$C_{t}-$ attributed cost of production and sales in time point $(\mathrm{t})$;

$C_{p}$ - planned cost price of production and sales;

$\Delta V_{t}$ - production volume change in time point $(\mathrm{t})$;

$k$ - business activity factor, defines as angle $\alpha$ tangent in time point $(\mathrm{t})$.

In theory, graphic of the sum of attributed price of cost and sales that depends on business activity level of industrial enterprise may vary in the range $0^{\circ}-180^{\circ}$, i.e. be a parabola (see Figure 7). But in practice neither the sum of attributed costs of production nor production volumes and sales of that production can be negative figures. 
So variations of the sum of attributed costs from geometrical point of view are possible in the range of variations of angle $\alpha$ tangent - from $0^{\circ}$ to $89,9^{\circ}$ (the task has no solution for tangent of $\alpha=90^{\circ}$ ). One should agree that graphical solution of the task of modeling of optimal attributed costs of production and sales is not always possible in practice, besides solutions are not always correct because strict unification of costs data with their graphical representation is required.

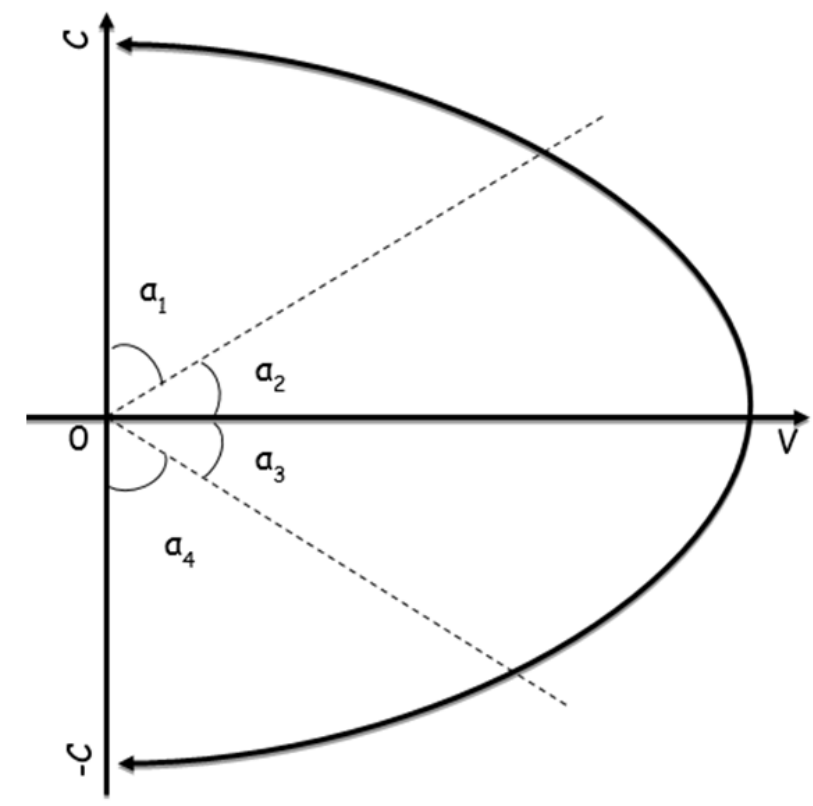

Figure 7. Theoretical interpretation of attributed costs variation depending on production volume and sales on industrial enterprise

It is also necessary to understand that constant and variable costs in attributed costs has different growth and decrease rate and it may depend and may not depend on production volumes and sales (Geroski \& Gugler, 2004). So in practice it is optimal to use regression models that describe dependence of two and more indicators.

\subsection{Correlation modeling of cost price}

Let us assume, that there is industrial enterprise with production volumes and attributed costs of this production are characterized by the following parameters (see Table 1).

Table 1. Volumes and attributed cost of production on industrial enterprise

\begin{tabular}{ccc}
\hline Period & Production volume (Y) & Attributed costs of production $(\mathrm{X})$ \\
\hline 1 & 37221 & 33456 \\
2 & 27201 & 26465 \\
3 & 32594 & 31539 \\
\hline
\end{tabular}

Then economic mathematical model of regression dependence of attributed costs and production volumes on industrial enterprise is derived (Table 2, Figure 8).

Table 2. Economic mathematical model of regression dependence between attributed costs and production volume on industrial enterprise

\begin{tabular}{|c|c|c|c|c|c|c|c|}
\hline \# & $\mathrm{Y}$ & $\mathrm{X}$ & $\mathrm{y}_{\mathrm{i}}-\overline{\mathrm{y}}$ & $x i-\dot{x}$ & $\left(\mathrm{y}_{\mathrm{i}}-\overline{\mathrm{y}}\right)^{*}\left(\mathrm{x}_{\mathrm{i}}-\dot{\mathrm{x}}\right)$ & $\left(\mathrm{x}_{\mathrm{i}}-\dot{\mathrm{x}}\right)^{2}$ & $\left(y_{i}-\bar{y}\right)^{2}$ \\
\hline 1 & 37221 & 33456 & 4882.3 & 2969.3 & 14497275.11 & 8816940.4 & 23837178.8 \\
\hline 2 & 27201 & 26465 & -5137.7 & -4021.7 & 20661982.78 & 16173802.8 & 26395618.8 \\
\hline 3 & 32594 & 31539 & 255.3 & 1052.3 & 268695.7778 & 1107405.4 & 65195.1 \\
\hline Total & 97016 & 91460 & 7E-12 & 7.3E-12 & 35427953.67 & 26098148.7 & 50297992.7 \\
\hline Average & 32338.67 & 30486.67 & & & & & \\
\hline \multicolumn{5}{|c|}{ Pair correlation coefficient } & 0.978 & \multicolumn{2}{|c|}{5} \\
\hline
\end{tabular}




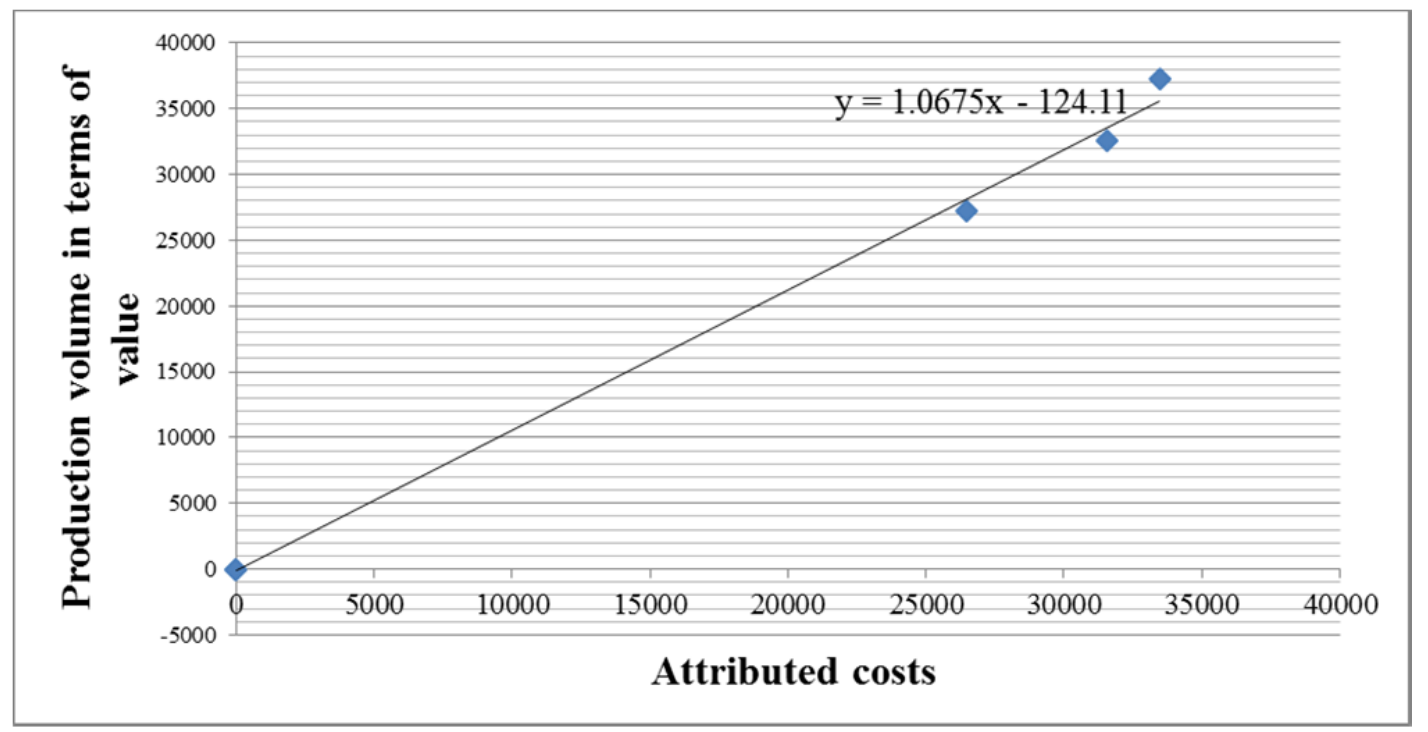

Figure 8. Model of regression dependence between attributed costs and production volumes on industrial enterprise

Calculation in presented economic and mathematical model allows making the following conclusions:

- firstly, attributed costs of production dependence of variations of production volume is relatively high, because in reverse model there will be equivalent results. Correlation between factors is high, according to Chaddock criterium;

- secondly, the model shows that in each iteration step growth of production volume on 1 conditional unit will potentiate attributed costs growth by 1.0675 conditional price units, i.e. growth rate of expenses are always in average $6 \%$ higher than sales growth rate. Revenue of an enterprise will be decreasing, respectively.

Calculations shows that in this example attributed costs grow disproportionately with the lower rate of production volume growth. Besides, disproportionate and consequently uncontrolled growth of spending causes reliable bearish trend of the revenue. To reveal and clarify the problem of surpassing attributed costs growth rate comparing production volume production and sales volume should be correlated with constant and(or) variable costs' items. In this step it may be empirically determined that the higher the value of some cost item in money terms the better is correlation between this item and production volume and consequently revenue and income.

So optimization solutions related not with setting normative values of spending but with setting limited thresholds are best solution in managing attributed costs of production and sales on industrial enterprise to achieve required economic benefits (revenue and income). In these thresholds attributed costs of production may vary from preset minimum to preset maximum depending on analogous variations of production volumes and sales. Enterprise should define critical production volume or control point. Beyond this point economy of scale is lost and costs per unit for production and sales of a unit of production do not decrease but on the contrary grow. Defining control point of critical production volume allows enterprise to develop and realize plans of sustainable functioning and development in the most adaptive manner (Stewart, 1991; Dudin, Ljasnikov, Pankov \& Sepiashvili, 2013).

\section{Conclusion}

Theoretical and methodological conclusions made in the work allow stating that management of attributed costs of production and sales on industrial enterprise is complicated task that requires different approaches to respective decisions. According to authors, attributed costs and sales management toolkit used now on industrial enterprise now requires adaptive and natural basis. Graphical modeling method and dependence deriving method (both proportional and non-proportional) between variation of attributed costs and production volumes may be used as such methodological basis. Besides, method of correlation regression modeling may be used that allows revealing patterns of changing of attributed costs depending on variability of production volume changes.

Theoretical and methodological thesis of the article allows stating that the greatest effectiveness from the point of view of relevance of result obtained have methods of economics and mathematical modeling based on regression deriving and determining correlation in variations of two interrelated economic indicators (attributed 
costs and production volume).

Graphical methods of modeling attributed costs of production require universalization and unification of used criteria, indicators and calculation methods. So use of graphic methods of modeling of attributed costs of operational activity of industrial enterprise in practice is limited.

\section{References}

Cooper, R. (1990). Cost classification in unit-based and activity-based manufacturing cost. Journal of Cost Management. Fall, 4-14.

Cooper, R., \& Kapla, R. S. (1991). The design of cost management systems. Cases and Readings. Prentice-Hall.

Deakins, D., Logan, D., \& Steele, L. (2001). The financial management of the Enterprise. London: Certified Accountants Educational Trust.

Drury, C. (2010). Managerial and production accounting. Moscow: UNITI-Dana.

Dudin, M. N., Ljasnikov, N. V., Pankov, S. V., \& Sepiashvili, E. N. (2013). Innovative foresight as the method for management of strategic sustainable development of the business structures. World Applied Sciences Journal, 8, 1086-1089. http://dx.doi.org/10.5829/idosi.wasj.2013.26.08.13550

German Industrial Output. Quote Ros Business Consulting. Retrieved October, 26, 2014, from http://quote.rbc.ru/macro/indicator/26/228.shtml

Geroski, P., \& Gugler, K. (2004). Corporate growth convergence in Europe. Oxford Economic Papers, 56, 597620. http://dx.doi.org/10.1093/oep/gpf055

Index of industrial production. Federal Statistics Agency. Retrieved October, 26, 2014, from http://www.gks.ru/bgd/free/b00_24/IssWWW.exe/Stg/d000/I000010R.HTM

Limitivski, M. A. (2010).Sustainable growth of a company and leverage effects. Russian Management Magazine, 2, 35-46.

Limitivski, M. A., Lobanova, N. E., Palamarchuk, V. P., \& Minasian, V. B. (2012). Corporate financial management. Moscow: Urait.

McConnell, K. R., \& Bru, S. L. (2009). Economics. Moscow: Infra-M.

Mochalova, L. A. (2010). Model of risk-oriented financial strategy of a corporation. M.F. Reshetnev Siberian State Aerospace Uniersity Gerald.

Popov, A. M., \& Sotnikov, V. N. (2012). Economic mathematical methods and models. Moscow: Urait.

Ross, S., Westerfield, R., \& Jordan, B. (2000). Basics of corporate finances. Moscow: Laboratory of Basic Knowledge.

Stewart, G. B. (1991). The Quest for Value. NY: Harper Business.

Total Cost Management Framework. (2012). An Integrated Approach to Portfolio, Program, and Project Management. PE CCE CEP. AACE International.

USA Industrial Output. Quote RosBusiness Consulting. Retrieved October, 26, 2014, from http://quote.rbc.ru/macro/indicator/24/98.shtml

\section{Copyrights}

Copyright for this article is retained by the author(s), with first publication rights granted to the journal.

This is an open-access article distributed under the terms and conditions of the Creative Commons Attribution license (http://creativecommons.org/licenses/by/3.0/). 